\title{
Editorials
}

\section{How to move from managing sick individuals to creating healthy communities}

\section{SHIFTING THE FOCUS FROM SICKNESS TO HEALTH}

The NHS is one of the most valued institutions in the UK $\mathrm{K}^{1}$ but its sustainability is threatened by a heavy bias towards managing illness in secondary care. The Wanless report ${ }^{2}$ and the Five Year Forward View ${ }^{3}$ and upcoming NHS Long Term Plan all argue for a reorientation towards keeping people well through community-level prevention.

Community-level prevention involves taking a localised approach to addressing the social determinants of health, which include housing, living and working conditions, education, food, and social networks. ${ }^{4}$ The strength of social relationships, for example, is a significant risk factor for mortality, as stronger relationships are associated with a $50 \%$ increased likelihood of survival than those with weaker social relationships. ${ }^{5}$ These non-medical 'causes of the causes' account for up to $90 \%$ of health outcomes ${ }^{6}$ and GPs see them at work in their patients' everyday lives. ${ }^{7}$ Despite the fact that individual lifestyle choices are heavily constrained by deeper socioeconomic conditions, the dominant political health narrative emphasises individual-level 'healthy choices' above societal change.

Less than $5 \%$ of the current health budget is spent on prevention ${ }^{8}$ and the 2012 Health and Social Care Act left overstretched public health teams with responsibility for addressing social determinants. ${ }^{9}$ Factors like fast food outlets, cheap alcohol, dangerous traffic, air pollution, and the lack of affordable fruit and vegetables drive up the prevalence of chronic disease. Left unchecked, these factors increase consultations, costs, and complexity for local GPs. General practice holds responsibility and financial risk for the health of listed populations, but does not have the means to address the 'upstream' non-biomedical factors that drive outcomes.

\section{AN EXPANDED ROLE FOR GENERAL \\ PRACTICE}

While Britain's demography, lifestyles, and burden of disease has evolved over recent decades, the basic formula of general practice remains unchanged. GPs reactively consult the subset of their listed population that has the means and motivation to seek care; managing problems after they have manifested in their patients' lives.

We envisage a near future where practices

\section{"Even though schooling, cycle lanes, and the price of chips have nothing to do with medicine, these social determinants have a much larger bearing on local health outcomes than diabetes management or antihypertensives.}

collaborate to share data and work alongside public health teams, patients, and local organisations to proactively engage with communities to make them more healthpromoting places to grow, learn, work, and age. GPs would help identify modifiable determinants and support the development of interventions to address them. Isolated examples of such practices exist (for example, Frome and Bromley-by-Bowl but much social prescribing aims to improve individuals' choices without addressing the physical, social, political, and economic structures that constrain the set of options that are available. We need a greater focus on fundamentally changing the physical and socio-political structure of society, for example, formal lobbying and community partnerships for better housing, bike lanes, benefits administration, public transport, clean air, and healthier school meals.

Is this the role of general practice? It already is for El Salvador's primary care system, Belgium's community health centres, New York's Montefiore and Cityblock Health groups, Alaska's Nuka System, and a number of deep end practices in Glasgow and Clyde.

\section{HOW DO WE GET THERE?}

System incentives to encourage engagement with population working include time, money, resources, support staff, and recognition. At an organisational level there needs to be shared information systems, databases, work plans, objectives, and governance structures between public health and primary care. Shared responsibility for health outcomes, risk, and finances would also engender deeper integration. Standardised working relationships between practices (or networks of practices) and public health link workers would help to nurture local crossorganisational communication, as would introducing named GP leads for population health.
GPs need public health knowledge and skills, as well as training in advocacy, community organising, policy, and local politics. These should be taught in medical schools, during GP training (alongside public health registrars), and as continuing professional development. As with safeguarding, not every GP will take a leading role in population health, but all need to be able to identify and flag issues in their practice populations.

To support prevention-oriented working NHS England and Clinical Commissioning Groups (CCGs) need to adopt longer-term funding horizons and work plans, and move to commissioning outcomes rather than activity. The NHS England Long Term Plan is an encouraging start, but even a decade is not long enough to capture benefits from addressing problems like childhood obesity where many of the costs and complications arise in adulthood.

There is room to experiment with paying GPs to engage with existing platforms for joint working: Health and Wellbeing Boards, Joint Strategic Needs Assessments, Better Care Fund activity, strategy development, and policy evaluation. This may involve collaborating with local authorities, local businesses, community groups, and patients to work on issues that influence health.

Support for emerging networks (for example PrimaPrev.com and the Faculty of Public Health Primary Care and Public Health Special Interest Groupl will help to identify barriers, opportunities, and lessons to promote community-level primary prevention.

Leaving the consultation room is a radical departure from traditional general practice but community engagement and population working are fundamental elements of national and international blueprints for primary care..$^{3,10,11}$ More guidance for localities and GP clusters would help to support the transition from rhetoric to reality. 


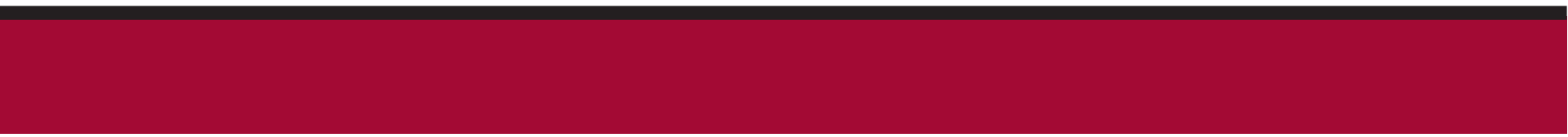

\section{... a reformed primary care sector stands to deliver real improvements by looking beyond biomedicine to influence the structures of society.}

\section{BARRIERS TO THIS VISION}

While effective community-level prevention could conceivably reduce demand and costs, the initial investments and time-lag represent high barriers to entry, especially in the current economic climate. Any gains will accrue to patients, GP surgeries, CCGs, and the wider local economy, however costs are mainly borne by councils and local businesses. This disconnect impedes action. Close collaboration between GPs and local public health teams is vital, but these relationships have fractured over recent years due to funding structures. ${ }^{12}$

CCGs are increasingly signalling a desire to invest more in preventative health. However, current interventions to improve population health often target small numbers of 'high risk' individuals which in isolation, are unlikely to deliver large improvements in health. ${ }^{13}$ National policy diktats perpetuate this approach and dominate the spending agenda, leaving little financial flexibility to fund wider initiatives in order to shift the burden of risk factors and disease in the population as a whole. ${ }^{13}$

To address these issues, CCGs and local authority co-commissioning and wider adoption of outcome-based commissioning may help to align organisational objectives. The national move towards primary care networks could provide an opportunity for primary care to have greater engagement with a wider array of health and nonhealth partners, going beyond the pure commissioning of clinical services. We are also encouraged by elements of the Sustainability and Transformation Plans which, if properly funded, could support some of the aspirations we have for prevention-orientated primary care

\section{MISSION IMPROBABLE?}

Preventing illness and keeping people well is good for patients, good for health workers, and good for national finances. Even though schooling, cycle lanes, and the price of chips have nothing to do with medicine, these social determinants have a much larger bearing on local health outcomes than diabetes management or antihypertensives. GPs are ideally positioned but underresourced to advocate for improving health outcomes of local populations by using their data and insight to identify social drivers of disease. With training, incentives, and support from public health teams, a reformed primary care sector stands to deliver real improvements by looking beyond biomedicine to influence the structures of society. As Rudolf Virchow said: 'Medicine is a social science and politics is nothing but medicine on a large scalé.

Change of this magnitude may sound improbable, requiring huge investment training, yet more system reform, and the concerted actions of politicians, commissioners, and practitioners. Nevertheless, we represent a new generation of population-minded doctors who are committed to making this form of general practice work, for the good of our patients, our practices, and the wider NHS.

\section{Luke N Allen,}

GP Academic Clinical Fellow, Nuffield Department of Primary Care Health Sciences, University of Oxford, Oxford.

\section{Eleanor Barry,}

Academic GP, Nuffield Department of Primary Care Health Sciences, University of Oxford, Oxford.

\section{Claire Gilbert,}

Public Health Registrar, Previous GP Academic Clinical Fellow, Leeds Teaching Hospitals NHS Trust, Leeds.

\section{Rory Honney,}

GP and Public Health Registrar, University of Southampton, Southampton.

\section{Eleanor Turner-Moss,}

Public Health Academic Clinical Fellow, University of Cambridge, Cambridge.

\section{Provenance}

Freely submitted; externally peer reviewed.

\section{Competing interests}

Luke Allen developed and maintains the PrimaPrev. com website, funded by a Global Challenges Research Fund grant. All authors are members of the Faculty of Public Health Special Interest Group. on Public Health and Primary Care.

\section{Acknowledgements}

The authors thank Ben Aimes, Ishraga Awad, Andrew Collins, Sara Kalde, Joe Mc Manners, Catherine Mountford, Jonathan Currie, and Harry Rutter for their contributions.

DOI: https://doi.org/10.3399/bjgp19X700337

\section{ADDRESS FOR CORRESPONDENCE}

Luke Allen

Nuffield Department of Primary Care Health Sciences, University of Oxford, Radcliffe Observatory Quarter. Woodstock Road, Oxford OX2 6GG, UK.

Email: drlukeallenagmail.com

\section{REFERENCES}

1. The King's Fund. What does the public think about the NHS? 2017. https://umw.kingsfund org.uk/publications/what-does-public-thinkabout-nhs\#nhs-founding-principles laccessed 5 Dec 2018).

2. Wanless D. Securing good health for the whole population. London: HM Stationery Office, 2004.

3. NHS England. Five Year Forward View. 2014 https://wnw.england.nhs.uk/wp-content/ uploads/2014/10/5yfrv-web.pdf laccessed 5 Dec 2018).

4. Public Health England. Research and analysis. Chapter 6: social determinants of health. 2017. https://wnw.gov.uk/government/publications/ health-profile-for-england/chapter-6-socialdeterminants-of-health (accessed 5 Dec 2018),

5. Holt-Lunstad J, Smith TB, Layton JB. Social Relationships and Mortality Risk: A Metaanalytic Review. PLoS Med 2010; 7(7): e1000316

6. McGovern L, Miller G, Hughes-Cromwick P. Health Policy Brief. The relative contribution of multiple determinants to health outcomes. Health Affairs, 2014. https://unw.rwjf.org/ content/dam/farm/reports/issue_briefs/2014/ rwjf415185 (accessed 5 Dec 2018).

7. Senior T. How chronic diseases thrive. $\mathrm{Br} J$ Gen Pract 2018; DOI: https://doi.org/10.3399/ bjgp18X698237

8. Office for National Statistics. UK Health Accounts 2016. ONS, 2018. https://wnw.ons. gov.uk/peoplepopulationandcommunity/ healthandsocialcare/healthcaresystem (accessed 5 Dec 2018).

9. British Medical Association. Funding for illhealth prevention and public health in the UK 2017. https://uww.bma.org.uk/-/media/files/ pdfs/collective\%20voice/policy\%20research/ public\%20and\%20population\%20health/ funding-for-ill-health-prevention-and-publichealth-in-the-uk.pdf (accessed 5 Dec 2018).

10. World Health Organization. The World Health Report 2008. Primary health care. Now more than ever. WHO, 2008.

11. World Health Organization. Astana Declaration on Primary Health Care: From Alma-Ata towards Universal Health Coverage and the Sustainable Development Goals (draft). http:// unw.who.int/primary-health/conference-phc/ DRAFT_Declaration_on_Primary_Health_ Care_28_June_2018.pdf (accessed 5 Dec 2018).

12. Royal Society for Public Health. The views of public health teams working in local authorities. Year 1. 2014. https://mww.rsph.org.uk/uploads/ assets/uploaded/cc2f33bd-8723-4c93a356b13e4c3a789f.pdf (accessed 5 Dec 2018).

13. Rose G. Sick Individuals and Sick Populations Int J Epidemiol 1985; 14(1): 32-38. 